\title{
Pharmacokinetic analyses of carboplatin in a patient with cancer of the fallopian tubes undergoing hemodialysis: A case report
}

\author{
TAKUMA WADA, TAKESHI FUKUDA, MASARU KAWANISHI, REIKO TASAKA, \\ KENJI IMAI, MAKOTO YAMAUCHI, MARI KASAI, YASUNORI HASHIGUCHI, \\ TOMOYUKI ICHIMURA, TOMOYO YASUI and TOSHIYUKI SUMI
}

\author{
Department of Obstetrics and Gynecology, Osaka City University \\ Graduate School of Medicine, Osaka 545-8585, Japan
}

Received April 5, 2016; Accepted June 10, 2016

DOI: $10.3892 /$ br.2016.714

\begin{abstract}
Opportunities for patients undergoing hemodialysis to receive chemotherapy are increasing. A combination of paclitaxel and carboplatin (TC) is first-line chemotherapy in patients with Müllerian cancer. However, the optimal dose and time interval between the end of carboplatin administration and initiation of hemodialysis remains to be elucidated. TC was administered to a patient with fallopian tube cancer undergoing hemodialysis. The paclitaxel regimen was determined to be $135 \mathrm{mg} / \mathrm{m}^{2}$ (total of $210 \mathrm{mg}$ ) over $3 \mathrm{~h}$. After paclitaxel administration, $125 \mathrm{mg}$ of carboplatin was administered over $1 \mathrm{~h}$ to achieve a target area under the concentration-time curve (AUC) of $5.0 \mathrm{mg} \bullet \mathrm{min} / \mathrm{ml} \mathrm{using} \mathrm{the} \mathrm{Calvert} \mathrm{formula.} \mathrm{The} \mathrm{time}$ interval between the end of carboplatin administration and hemodialysis initiation was $1 \mathrm{~h}$ at the first cycle, $16 \mathrm{~h}$ at the second cycle and $20 \mathrm{~h}$ at the third cycle, and the AUC obtained was 2.86, 4.16 and $6.0 \mathrm{mg} \bullet \mathrm{min} / \mathrm{ml}$, respectively. The desired AUC of free platinum was demonstrated and only mild side effects were observed at the third cycle. Therefore, hemodialysis was initiated $20 \mathrm{~h}$ after completion of carboplatin infusion at cycles 4-6. The total chemotherapy planned was completed without severe adverse events. Measurement of the concentration of free platinum subsequent to administration is useful for determination of the optimal dose of carboplatin and time interval following administration to obtain an adequate AUC. The present study suggests that carboplatin can be administered to a patient undergoing hemodialysis, and that an
\end{abstract}

Correspondence to: Dr Takeshi Fukuda, Department of Obstetrics and Gynecology, Osaka City University Graduate School of Medicine, 1-4-3 Asahimachi, Osaka 545-8585, Japan

E-mail: takeshif@med.osaka-cu.ac.jp

Key words: carboplatin, concentration of free platinum, hemodialysis, Müllerian cancer, tubal cancer adequate interval between the end of carboplatin administration and hemodialysis initiation may be $\sim 20 \mathrm{~h}$.

\section{Introduction}

The prognosis of patients with renal failure has improved due to the refinements and advances in hemodialysis methods. Renal failure can lead to impairment of the immune system, and therefore, patients undergoing hemodialysis can suffer from various types of cancer. Consequently, the opportunity to undergo chemotherapy for patients being treated by hemodialysis is increasing.

A combination of paclitaxel and carboplatin (TC) is first-line chemotherapy for patients with Müllerian cancer. There are few studies on the TC pharmacokinetics in hemodialysis patients with Müllerian cancer. Therefore, determination of the administration method (dose and time interval between administration of anticancer agent and hemodialysis initiation) is difficult. The number of dialysis patients undergoing TC is increasing, and therefore, the establishment of the optimal method for administration of anticancer agents is important.

Certain previous studies have suggested that paclitaxel pharmacokinetics are not affected by hemodialysis (1-4). In the present study, carboplatin concentrations were measured in a patient with fallopian tube cancer (FTC) with chronic renal failure who required hemodialysis.

\section{Case report}

A 73-year-old Japanese woman with chronic renal failure associated with type-2 diabetes mellitus, who had undergone hemodialysis three times a week for 3 years, presented with abdominal distension. Magnetic resonance imaging revealed a tumor in the left fallopian tube (diameter, $9 \mathrm{~cm}$ ). Carcinoma of the left adnexa was suspected, and the patient underwent abdominal total hysterectomy, bilateral salpingo-oophorectomy, partial omentectomy and pelvic lymphadenectomy. Histology revealed an endometrial adenocarcinoma (grade 2) in the left fallopian tube. The patient underwent optimal surgery and was diagnosed 
Table I. CBDCA dose, AUC of free platinum and interval between completion of CBDCA administration and the initiation of hemodialysis.

\begin{tabular}{|c|c|c|c|c|c|c|}
\hline \multirow[b]{2}{*}{ First author, year } & \multirow[b]{2}{*}{ Type of cancer } & \multirow[b]{2}{*}{$\begin{array}{l}\text { CBDCA, } \\
\text { mg/body }\end{array}$} & \multicolumn{2}{|l|}{ Hemodialysis } & \multirow[b]{2}{*}{$\begin{array}{c}\mathrm{AUC} \\
\mathrm{mg} \bullet \mathrm{min} / \mathrm{ml}\end{array}$} & \multirow[b]{2}{*}{ Refs. } \\
\hline & & & $\begin{array}{c}\text { Interval after } \\
\text { CDBCA administration, } \mathrm{h}\end{array}$ & Duration, $\mathrm{h}$ & & \\
\hline Watanabe, 2002 & Ovarian & 125 & 16 & 4 & 4.4 & (1) \\
\hline Yoshida, 2009 & Ovarian & 125 & 1 & 4 & 1.0 & (3) \\
\hline Kodama, 2010 & Ovarian & 150 & 24 & 3 & 4.6 & (4) \\
\hline Suzuki, 1997 & Merkel cell & 150 & 2 & 4 & 4.8 & (12) \\
\hline Chatelut, 1994 & Ovarian & 150 & 24 & 4 & 6.7 & (13) \\
\hline Yokoyama, 2006 & Ovarian & 200 & 16 & 4 & 5.7 & (14) \\
\hline Fong, 2014 & Neurocrine & 200 & 1.5 & 3.5 & 2.9 & (15) \\
\hline \multirow[t]{3}{*}{ Wada, 2016} & FT & 125 & 1 & 4 & 2.9 & (Present study) \\
\hline & & 125 & 16 & 4 & 4.2 & \\
\hline & & 125 & 20 & 4 & 6.0 & \\
\hline
\end{tabular}

AUC, area under the concentration-time curve; CBDCA, carboplatin; FT, fallopian tube.

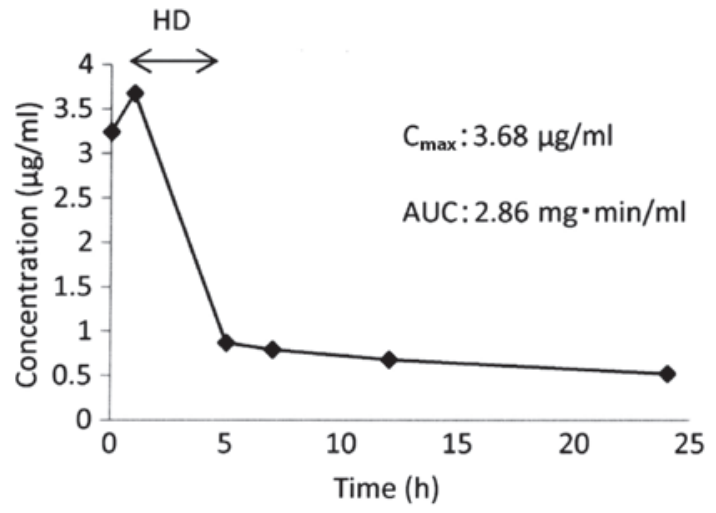

Figure 1. Free platinum concentration in the plasma of HD patients. HD was initiated at $1 \mathrm{~h}$ after completion of carboplatin administration. HD, hemodialysis; $\mathrm{C}_{\max }$, maximum plasma concentration; $\mathrm{AUC}$, area under the curve.

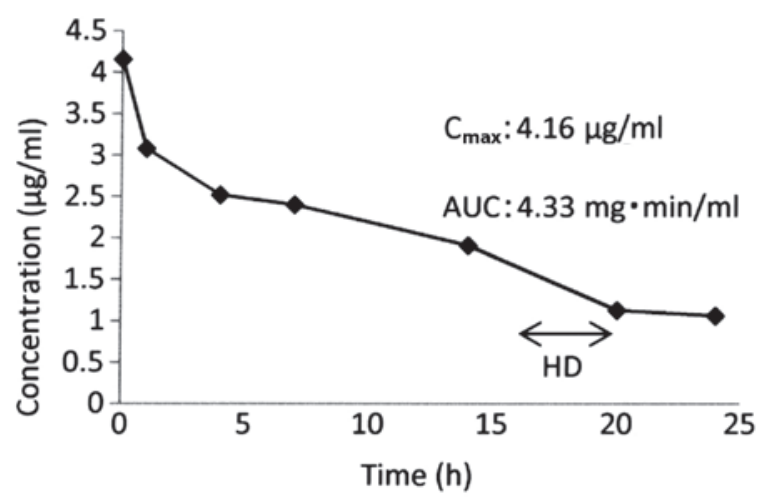

Figure 2. Free platinum concentration in the plasma of HD patients. HD was initiated at $16 \mathrm{~h}$ after completion of carboplatin administration. HD, hemodialysis; $\mathrm{C}_{\max }$, maximum plasma concentration; $\mathrm{AUC}$, area under the curve.

with stage-IC3 (International Federation of Gynecology and Obstetrics) FTC. Postoperatively, the patient was

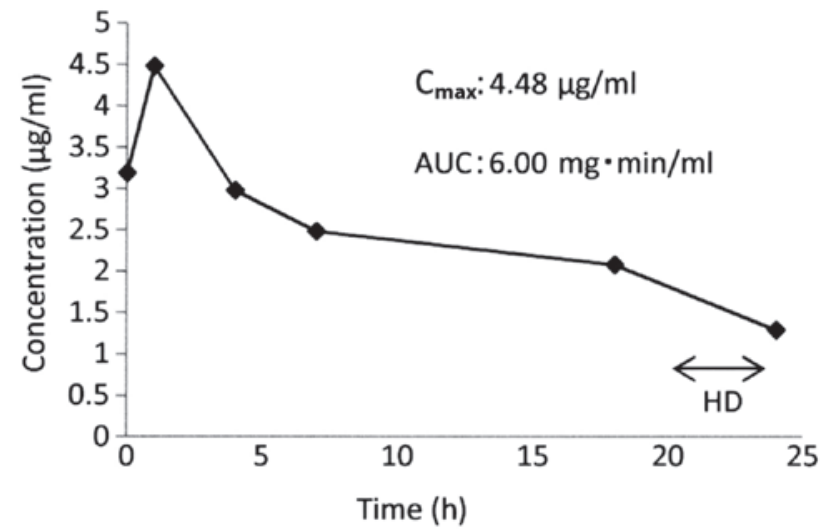

Figure 3. Free platinum concentration in the plasma of HD patients. HD was initiated at $20 \mathrm{~h}$ after completion of carboplatin administration. HD, hemodialysis; $\mathrm{C}_{\max }$, maximum plasma concentration; $\mathrm{AUC}$, area under the curve.

administered TC (i.v.). The chemotherapy regimen was 6 cycles, with 1 cycle every 3 weeks.

The paclitaxel regimen was determined to be $135 \mathrm{mg} / \mathrm{m}^{2}$ (total of $210 \mathrm{mg}$ ) over $3 \mathrm{~h}$. After paclitaxel administration, carboplatin was administered over $1 \mathrm{~h}$. The carboplatin dose was calculated according to the Calvert formula [target area under the concentration-time curve (AUC): $5 \mathrm{mg} \bullet \mathrm{min} / \mathrm{ml}$ (5). The glomerular filtration rate (GFR) was determined to be zero as the urinary volume per day of the patient was $0 \mathrm{ml}$. Therefore, the carboplatin dose was calculated as $125 \mathrm{mg}$.

Hemodialysis was initiated $1 \mathrm{~h}$ after completion of carboplatin infusion and carried out for $4 \mathrm{~h}$. Samples of heparinized blood were collected at specific times. The blood samples were centrifuged at $1,350 \times \mathrm{g}$ for $5 \mathrm{~min}$ at $4^{\circ} \mathrm{C}$. The plasma aliquots were centrifuged at $1,350 \mathrm{x} \mathrm{g}$ for $15 \mathrm{~min}$ at $4^{\circ} \mathrm{C}$ in an Amicon ${ }^{\circledR}$ system (Millipore, Bedford, MA, USA) for evaluation of the free platinum based on the method of LeRoy et al (6). 
The maximum plasma concentration $\left(\mathrm{C}_{\max }\right)$ of the free platinum was $3.68 \mu \mathrm{g} / \mathrm{ml}$ and the AUC of the free platinum was $2.86 \mathrm{mg} \bullet \mathrm{min} / \mathrm{ml}$ (Fig. 1). Adverse events were evaluated based on the Common Terminology Criteria for Adverse Events set by the National Cancer Institute (version 4) (7). Adverse events of grade 3 or 4 were not observed.

Due to the low AUC of free platinum in the first cycle of chemotherapy, the time interval between the end of carboplatin infusion and the start of hemodialysis was extended in the next cycle. The time interval was prolonged to $16 \mathrm{~h}$ at the second cycle and to $20 \mathrm{~h}$ at the third cycle. The $\mathrm{C}_{\max }$ of the drug in the serum at the second and third cycles were 4.16 and $4.48 \mu \mathrm{g} / \mathrm{ml}$, and the AUCs were 4.33 and $6.00 \mathrm{mg} \bullet \mathrm{min} / \mathrm{ml}$, respectively (Figs. 2 and 3). Grade-3 leukocytopenia and neutropenia were observed; however, chemotherapy was (in general) well-tolerated.

The desired AUC of free platinum was demonstrated and only mild side effects were observed at the third cycle. Therefore, hemodialysis was initiated $20 \mathrm{~h}$ after completion of carboplatin infusion at cycles 4-6. The total chemotherapy planned was completed without severe adverse events. Recurrence was not observed at the 22-month follow-up.

\section{Discussion}

The prognosis of patients with renal failure has improved due to the advances in hemodialysis methods. In addition, TC is being administered increasingly often in patients with Müllerian cancer who require hemodialysis. However, the optimal drug dose and timing of hemodialysis remain to be elucidated. In the present study, TC was administered safely to a patient with FTC requiring hemodialysis, and the carboplatin pharmacokinetics were examined.

Paclitaxel is metabolized extensively by the hepatic cytochrome $\mathrm{P} 450$ and secreted into bile, with $<10 \%$ being extracted by the kidneys (8). Therefore, it is assumed that paclitaxel pharmacokinetics are slightly affected by renal function. It has been reported that the $\mathrm{C}_{\max }$, $\mathrm{AUC}$ and attenuation pattern of paclitaxel in patients with renal failure requiring hemodialysis are comparable with the pharmacokinetics of patients with normal renal function, and that paclitaxel can be administered safely for patients with renal failure without hepatic dysfunction prior or subsequent to hemodialysis at the same dose as patients with normal renal function (1-4,9). Therefore, in this instance, paclitaxel was administered in a patient with renal failure instead of measuring the paclitaxel concentration in blood.

Carboplatin is metabolized almost completely by the kidneys, and renal function affects its pharmacokinetics. In general, the carboplatin dose administered is calculated based on the Calvert formula (1). In practice, the GFR in hemodialysis patients is approximately zero, so the carboplatin dose should be the target AUC x25. Carboplatin can be dialyzed readily during hemodialysis because of its low binding capacity to proteins and intermediate molecular weight (10). Therefore, carboplatin is excreted mainly during hemodialysis in patients with renal failure, and its AUC is dependent upon the carboplatin dose and timing of hemodialysis $(11,12)$.

In the present study, hemodialysis was initiated $1 \mathrm{~h}$ after completion of the administration of carboplatin $(125 \mathrm{mg})$ at the first chemotherapy cycle, and the target AUC was not achieved. Therefore, the time interval between the end of carboplatin administration and beginning of hemodialysis was prolonged. An AUC of $4.33 \mathrm{mg} / \mathrm{ml} \bullet \mathrm{min}$ was obtained at the second chemotherapy cycle when hemodialysis was started $16 \mathrm{~h}$ after carboplatin administration. An adequate AUC of $6.00 \mathrm{mg} / \mathrm{ml} \bullet \mathrm{min}$ was achieved at the third chemotherapy cycle at a time interval of $20 \mathrm{~h}$. Therefore, hemodialysis was initiated $20 \mathrm{~h}$ after completion of carboplatin infusion at cycles 4-6. The total chemotherapy planned was completed without severe adverse events.

Several studies have described the carboplatin dose, AUC of free platinum and interval between completion of administration and initiation of hemodialysis in hemodialysis patients $(1,3,4,12-15)$ (Table I). In this way, the optimal dose of carboplatin and timing of hemodialysis remains controversial. Therefore, guidelines for the optimal method to administer carboplatin in hemodialysis patients are required. Measurement of the concentration of free platinum following administration may be useful for determination of the optimal dose of carboplatin and interval following administration to obtain an adequate AUC. The present study suggests that carboplatin can be administered to a patient undergoing hemodialysis, and that an adequate interval between the end of carboplatin administration and hemodialysis initiation could be $\sim 20 \mathrm{~h}$.

\section{References}

1. Watanabe M, Aoki Y, Tomita M, Sato T, Takaki Y, Kato N, Kikuchi M, Kase H and Tanaka K: Paclitaxel and carboplatin combination chemotherapy in a hemodialysis patient with advanced ovarian cancer. Gynecol Oncol 84: 335-338, 2002.

2. Tomita M, Kurata H, Aoki Y, Tanaka K and Kazama JJ: Pharmacokinetics of paclitaxel and cisplatin in a hemodialysis patient with recurrent ovarian cancer. Anticancer Drugs 12: 485-487, 2001.

3. Yoshida H, Sumi T, Abe K and Ishiko O: Pharmacokinetics of paclitaxel and carboplatin in a hemodialysis patient with advanced ovarian cancer. Eur J Gynaecol Oncol 30: 583-585, 2009.

4. Kodama J, Sasaki A, Masahiro S, Seki N, Kusumoto T, Nakamura K, Hongo A and Hiramatsu Y: Pharmacokinetics of combination chemotherapy with paclitaxel and carboplatin in a patient with advanced epithelial ovarian cancer undergoing hemodialysis. Oncol Lett 1: 511-513, 2010.

5. Calvert AH, Newell DR, Gumbrell LA, O'Reilly S, Burnell M, Boxall FE, Siddik ZH, Judson IR, Gore ME and Wiltshaw E: Carboplatin dosage: Prospective evaluation of a simple formula based on renal function. J Clin Oncol 7: 1748-1756, 1989.

6. LeRoy AF, Wehling ML, Sponseller HL, Friauf WS, Solomon RE, Dedrick RL, Litterst CL, Gram TE, Guarino AM and Becker DA: Analysis of platinum in biological materials by flameless atomic absorption spectrophotometry. Biochem Med 18: 184-191, 1977.

7. National Cancer Institute, National Institutes of Health, US Department of Health and Human Services: Common terminology criteria for adverse events (CTCAE) version 4.0. NIH Publication no. 09-5410, Bethesda, MD, 2009.

8. Longnecker SM, Donehower RC, Cates AE, Chen TL, Brundrett RB, Grochow LB, Ettinger DS and Colvin M: High-performance liquid chromatographic assay for taxol in human plasma and urine and pharmacokinetics in a phase I trial. Cancer Treat Rep 71: 53-59, 1987.

9. Woo MH, Gregornik D, Shearer PD, Meyer WH and Relling MV: Pharmacokinetics of paclitaxel in an anephric patient. Cancer Chemother Pharmacol 43: 92-96, 1999.

10. Hiraike M, Hiraki Y, Misumi N, Hanada K, Tsuji Y, Kamimura H, Karube Y and Kashiwabara K: Pharmacokinetics of carboplatin in a hemodialysis patient with small-cell lung cancer. Cancer Chemother Pharmacol 69: 845-848, 2012. 
11. Koeller JM, Trump DL, Tutsch KD, Earhart RH, Davis TE and Tormey DC: Phase I clinical trial and pharmacokinetics of carboplatin (NSC 241240) by single monthly 30-minute infusion. Cancer 57: 222-225, 1986.

12. Suzuki S, Koide M, Sakamoto S and Matsuo T: Pharmacokinetics of carboplatin and etoposide in a haemodialysis patient with Merkel-cell carcinoma. Nephrol Dial Transplant 12: 137-140, 1997.

13. Chatelut E, Rostaing L, Gualano V, Vissac T, De Forni M, Ton-That H, Suc JM, Houin G and Canal P: Pharmacokinetics of carboplatin in a patient suffering from advanced ovarian carcinoma with hemodialysis-dependent renal insufficiency. Nephron 66: 157-161, 1994
14. Yokoyama Y, Futagami M, Higuchi T and Mizunuma $\mathrm{H}$ : Pharmacokinetic analysis of paclitaxel and carboplatin in a patient with advanced ovarian cancer during hemodialysis - case report. Eur J Gynaecol Oncol 27: 437-439, 2006.

15. Fong MK, Fetterly GJ Jr, McDougald LJ and Iyer RV: Carboplatin pharmacokinetics in a patient receiving hemodialysis. Pharmacotherapy 34: e9-e13, 2014. 